\title{
Identification of Factors Affecting Employees' Empowerment in Airports of Mazandaran Province
}

\author{
Nadeya Narenji
}

M.A Student of Education, Tonekabon branch, Islamic Azad University, Tonekabon, Iran

*Seyed Sadra Nojabaee

Assistant Professor Department of Education, Tonekabon Branch, Islamic Azad University, Tonekabon, Iran

*Corresponding Author E-mail: nojabaees@yahoo.com

\section{Doi:10.5901/mjss.2015.v6n3s2p747}

\begin{abstract}
The main target of the present research is to identify factors affecting employees' empowerment in Mazanadarn province airports. Research methodology was descriptive survey. The statistical population of the research included all employees of airports in Mazandaran Province. Based on Camery's proposal (1973), 350 people were selected by means of cluster random sampling. A researcher-made questionnaire was used for collecting data on factors affecting employees' empowerment. This questionnaire contained 44 questions which were designed based on theories and literature on empowerment. Data were analyzed by means of exploratory factor analysis. Reliability was tested by means of Cronbach's alpha (0.947). The results of principal components analysis and Varimax Rotation showed that the test is saturated with 8 factors which in general predict $62.991 \%$ of total variance. These 8 factors were significance of job, communications, job security, significance of occupational activities, organizational belonging, working environment, appreciation, and participation \& group working. The final validity of the 8 factors was also estimated.
\end{abstract}

Keywords: empowerment, feasibility, validity, reliability, norm

\section{Statement of the Problem}

Organizations pay attention to their employees' empowerment in order to reduce their costs, improve their performances, and reach higher levels of flexibility. Employees' empowerment is very important for effectiveness and innovation of organization (Spreitzer, 2005). Empowerment refers to conditions in which one can use his or her power when necessary (Narayan, 2006). Empowerment is the process of development and increases employees' power for solving problems and promotion of their political and social insight. It enables employees to identify environmental factors and control them (Cartwright, 2002).

G. Drydyk (2008) found that people become empowered in order to develop their abilities to make decisions and influence important and strategic selections and remove barriers. Empowerment can help people with controlling their assets collectively and individually. It influences their performances and allows them to use their abilities against harsh conditions. Karakoc (2009) investigated the studies conducted by previous researchers and found that factors like tendency to development, having critical thinking skill, acceptance of change, abundant self-confidence, coordination, dynamic structure, performance evaluation, feedback, reward, support, education, communications, the level of authority submitted to employees, motivation and encouragement by management, creation of participation culture, common vision, emphasis on flexibility and independence of thought, information sharing and management trust in employees can affect employees empowerment. Ergeneli et al (2007) investigated psychological empowerment (significance, influence, autonomy, and competency) and its relationship with trust in managers. They investigated 220 managers of Turkey Banks (Ankara). Their results showed that there is a direct and considerable relationship between cognition-based trust and managers' psychological empowerment. Yim (2008) considered two factors: information resources for performance (customer orientation against supervisor orientation) and reward system (result orientation against behavior orientation) as effective on employees' empowerment. He believes that information resources on performance by customers create more empowerment in comparison with supervisors.

Based on the above theoretical roots, we will try to acquire necessary indices for operational definition of employees' empowerment and research instrument will be designed based on this definition. These indices include: 
1. specific targets, responsibilities and authorities in an organization: employees must know about their responsibilities, targets and mission and working stages and processes.

2. jobs enrichment and employees' occupational promotion: the organization should table measures in order to update employees' technical and specialized needs and increase in their occupational contents. Furthermore, job rotation technique should be used for satisfaction of succession planning.

3. Organizational belonging and spirits: in order to satisfy this factor, employees should be helped with solving their problems. Appropriate fields should be provided for invention, innovation and creativity in employees and senior management should make sure that employees tend to do affairs which have been submitted to them.

4. trust, friendship and honesty: organizations create positive and friendly working relations among employees and increase trust among managers and employees.

5. 5.recognition and appreciation: consistency of rewards and salaries with the work employees do, appropriate distribution of welfare facilities in organization and consistency between employees' promotion and their competencies can be important.

6. group work and participation: use of employees' ideas and opinions in decisions and their cooperation with improvement and promotion of organizational affairs, delegation of power to employees in different levels, employees' participation in proposing for improvement of affairs and control of the employees' affairs by them can be effective in increasing employees' empowerment in organizations.

7. communications: this includes establishment of relationship and easy access of employees to managers and supervisors, clarity of employees' working communications with managers and supervisors and employees knowledge about current affairs of the company in relation with their working fields.

8. working environment: working environment is one of the effective factors which is emphasized in organizations. Attention to employees' health and safety at work environment, facilitation of employees' occupational promotion, reduction in pressure and tensions at work environment can be related to work environment.

9. optimization of working processes and methods: clarity of circulation of work and information within the organization, documentation of working methods and periodical revision of working methods and simplification of affairs are effective factors in optimization of processes and working methods.

10. information, knowledge and occupational skill: in order to satisfy this factor, it is useful to have facilities for development of occupational skills in organization, to have effective training in organization and technical knowledge about positions.

Considering the importance of the research subject, the author would like to answer the following questions:

1. what are the factors which influence employees' empowerment?

2. what are the dimensions (indices) of the factors which influence employees' empowerment of Mazandaran Province airports?

3. what is the most appropriate model for Mazandaran province airports employees' empowerment?

\section{Methodology}

The present research is an exploratory research considering the application of factor analysis technique. The statistical population of the research included all employees of Mazandaran province airports. 350 employees were selected by means of cluster random sampling method and based on Kameri's proposal (1973) and considering statistical model (factor analysis). After correction and scoring and elimination of unwanted questionnaires, 349 questionnaires were analyzed.

\section{Data Gathering Instrument}

First, we investigated research literature and theoretical fundamentals and collected factors which influence employees' empowerment. Then we designed a questionnaire containing 44 questions based on 4-point Likert scale. Content validity of the questionnaire was verified by three professors. Cronbach's alpha was equal to 0.947 .

Common descriptive statistical methods like frequency distribution, central indices and scattering indices were used for descriptive analysis of data. Cronbach's alpha was used for investigation of internal consistency and reliability of the questionnaire. Principal components analysis (factor analysis) was used for investigation of validity. Varimax rotation was used for determination of an appropriate model for empowerment. Structural equations modeling technique and confirmatory factor analysis were used for inferential analysis. 
Statistical operations were conducted by means of LISREL and SPSS software.

\section{Findings}

The statistical indices of the questionnaire for investigation of factors affecting Mazandaran Province airports employees show that the range of test scores are between 44 and 176, their mean value is equal to 149.67 and standard deviation is equal to 14.239. data show that the distribution has a negative equal to -1.094 . therefore, it can be said that the respondents' mean score lies between 148.17 and 151.77 with 95\% of certainty. In the present research, by reliability we mean internal consistency of the questionnaire i.e. interference of all questions in terms of the type of common feature (employees' empowerment). Reliability coefficient (Cronbach's alpha) was equal to 0.947 . correlationcoefficients of each question with total score was positive and its maximum value was equal to 0.635 . all these coefficients are statistically significant. Further, when a question is eliminated, reliability coefficient (which is equal to 0.947 ) is reduced.

Factor analysis: first of all, it must be said that the following assumptions must be considered before factor analysis. 1. Sampling adequacy index (KMO), it must be at least equal to 0.7 and preferably above that. 2 . The result of Bartlett test of sphericity must be significant statistically. 3. Factor loading of each question in factor matrix and rotated matrix must be at least equal to 0.3 and preferably above that. 4 . Each of the factors must belong to at least three questions. 5. The factors must be reliable enough.

In the present research, KMO value was equal to 0.909 and significance level of Barttelt'ssphericity test is lower than 0.0001 . Therefore, it can be concluded that implementation of factor analysis based on the correlation matrix resulted from the studied sample group will be justifiable. Moreover, the primary output of the computer also shows that the determinant value of correlation matrix is a non-zero number which shows that the factors can be extracted based on these data. in order to determine the number of significant factors research instruments (all questions) have been saturated, three main indices have been considered: 1. Eigen value, 2. The ratio of the predict variance by each factor and rotated figure of Eigen values which is called scree.

Primary statistical indices of principal components showed that:

Eigen values of 10 factors were above 1 . These 10 factors predict $62.991 \%$ of total variables variance. If we extract 8 factors based on the results of implementation of factor analysis and indices which have been mentioned above (especially figure 1), $58.184 \%$ of the total variance will be predicted. The first factor has an Eigen value equal to 13.82 and predicts $31.43 \%$ of total variance and $49.893 \%$ of joint variance of the variables. Finally, the eighth factor has an Eigen value equal to 1.18 and predicts $2.54 \%$ if total variance of the variables.

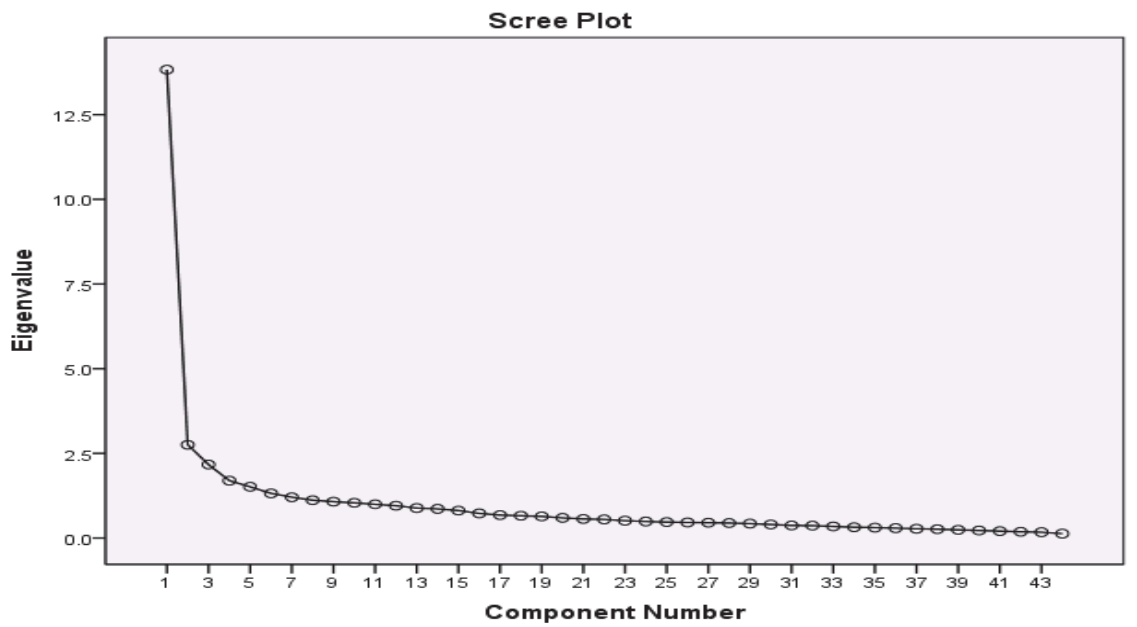

Figure 1. Questionnaire dimensions figure based on Eigen values

Eigen values of these 8 factors and variance percentages of them have been shown in table 1. 
Table 1. Eigen value, variance prediction percentage and compressive percentage of the factors

\begin{tabular}{|c|c|c|c|}
\hline Factor & Eigen value & Variance percentage & Compressive percentage \\
\hline 1 & 13.829 & 31.428 & 31.428 \\
\hline 2 & 2.754 & 6.258 & 37.687 \\
\hline 3 & 2.169 & 4.930 & 42.617 \\
\hline 4 & 1.694 & 3.851 & 46.468 \\
\hline 5 & 1.514 & 3.440 & 49.908 \\
\hline 6 & 1.319 & 2.999 & 52.907 \\
\hline 7 & 1.205 & 2.738 & 55.645 \\
\hline 8 & 1.117 & 2.539 & 58.184 \\
\hline
\end{tabular}

As it was mentioned before, the factors extracted were transferred to new axes using varimax rotation in order to make it possible to identify the general shape of variables and identify their constructs structure. The matrix of rotated factors for the questions of the questionnaire has been shown in table 2 .

Table 2. Matrix of rotated factors for the 44-item questionnaire by means of varimax rotation

\begin{tabular}{|c|c|c|c|c|c|c|c|c|}
\hline Question /factor & 1 & 2 & 3 & 4 & 5 & 6 & 7 & 8 \\
\hline $\mathrm{q} 1$ & .756 & & & & & & & \\
\hline q2 & .752 & & & & & & & \\
\hline$q 4$ & .716 & & & & & & & \\
\hline$q^{3}$ & .711 & & & & & & & \\
\hline q5 & .640 & & & & & & & \\
\hline$q 6$ & .528 & & & & & & & \\
\hline q23 & & .727 & & & & & & \\
\hline q24 & & .661 & & & & & & \\
\hline q22 & & .646 & & & & & & \\
\hline q25 & & .632 & & & & & & \\
\hline q21 & & .562 & & & & & & \\
\hline q20 & & .480 & & & & & & .404 \\
\hline q33 & & & .651 & & & & & \\
\hline q31 & & & .622 & & & & & \\
\hline q28 & & & .561 & & & & & \\
\hline q29 & & & .556 & & & & & \\
\hline q30 & & & .541 & & & & & \\
\hline$q 27$ & & & .455 & & & & & \\
\hline q26 & & .396 & .441 & & & & & \\
\hline q32 & & .357 & .390 & & & & & \\
\hline q34 & & & & .755 & & & & \\
\hline q35 & & & & .685 & & & & \\
\hline q36 & & & & .666 & & & & \\
\hline q38 & & & & .598 & & & & \\
\hline q37 & & & & .531 & & & & \\
\hline$q 10$ & & & & & .799 & & & \\
\hline q8 & & & & & .694 & & & \\
\hline q9 & & & & & .592 & & & \\
\hline$q 11$ & & & & & .576 & & & \\
\hline$q 7$ & & .431 & & & .467 & & & \\
\hline$q 12$ & & & & & .386 & & .384 & \\
\hline$q 42$ & & & & & & .738 & & \\
\hline$q 41$ & & & & & & .732 & & \\
\hline$q 40$ & & & & & & .621 & & \\
\hline$q 44$ & & & & & & .552 & & \\
\hline q39 & & & & & & .532 & & \\
\hline$q 43$ & & & & & & .421 & & \\
\hline$q 16$ & & & & & & & .713 & \\
\hline$q 15$ & & & & & & & .615 & \\
\hline$q 14$ & & & & & & & .589 & \\
\hline$q 13$ & & .369 & & & & & .458 & \\
\hline$q 18$ & & & & & & & & .684 \\
\hline q17 & & & & & & & & .631 \\
\hline$q 19$ & & & & & & & & .624 \\
\hline
\end{tabular}


The following items are inferred from the above matrix.

1. Al questions have factor loadings and no question was eliminated.

2. The questions number $7,12,26,32,13$, and 20 are concentrated on two factors and have relative complexity.

3. Other questions are very simple and lack complexity.

4. The greatest coefficient in the structure matrix (correlation between each question and factor) with factor loadings above 0.7 belongs to the following questions: 1, 2, 10, 4, 3, 16, 23, 34, 41, 42.

5. The questions $24,5,22,33,31,35,36,38$ and 8 have factor loadings above 0.6 .

6. Other questions have factor loadings smaller than 0.6 .

7. According to factors structures matrix, the questions which are commonly correlated with one factor constitute a test part. These questions were nominated in terms of the maximum factor loading as follows:

First factor: questions number 1, 3, 2, 4, 5, 6 (significance and clarity of job)

Second factor: questions 25, 24, 23, 22, 21, and 20 (communications)

Third factor: questions 33, 32, 30, 31, 28, 27, 26 and 29 (job security)

Fourth factor: questions $34,35,36,37$ and 38 (significance of occupational activities)

Fifth factor: questions 7, 8, 9, 10,11, 12 (organizational belonging)

Sixth factor: questions 39, 40, 41, 42, 43, 44 (working environment)

Seventh factor (questions 13, 14, 15, and 16 (appreciation and recognition)

Eighth factor: questions 17, 18, 19 (participation and working group)

\section{Conclusion and Discussion}

The results of the present research showed that factors affecting employees' empowerment in airports of Mazandaran Province include: significance and clarity of job, communications, and job security, significance of occupational activities, organizational belonging, working environment, appreciation and recognition, and participation and group work. This result is consistent with the results of studies conducted by farhangi and eskandari (2003), Norouzi (2005), Pak Tinat and Fathizadeh (2008), Shanon (2002), Betnagar (2007), Ergenli et al (2007) and Tim (2008).

Each of the 8 factors includes indices as follows:

First factor: clarity and significance of job includes the following indices:

1. Employees' knowledge about their duties and responsibilities, 2. Employees' knowledge about organizational targets and mission, 3. Employees' knowledge about working processes and stages, 4. Domination over skills necessary for doing work, 5. Up-to-date technical and specialized information and addition to job content, 6. Organizational contribution to eliminate employees' personal problems.

Second factor: communications which include the following indices:

1. Employees' cooperation in presenting recommendations for improvement of work processes, 2. Self-control, 3. Managers and supervisors trust in employees and vice versa, 4. Delegation of power to employees in different levels, 5. Employees' knowledge about organizational affairs in relation to their working area, 6 . Clarity of work and information circulation in organization,

Third factor: occupational security which includes the following indices:

1. Establishment of relationship and easy access of employees to managers and supervisors, 2. Presence of effective and efficient training within the organization, 3.Clarity of working communications between employees and managers, 4.Appropriate situations for employees' occupational promotion, 5.Managers' attempts to reduce working environment pressure and tensions, 6.Facilities for development of occupational skills within organization, 7.Documentation of working methods and processes, 8.Periodical revision of correction of working methods and simplification of affairs.

Fourth factor: significance of occupational activities whichinclude the following indices:

1. Appropriate educational level, 2. Employees' high self-confidence, 3.Technical and specialized information in relation to positions, 4.Significance of working activities for employees, 5. Enough working experience,

Fifth factor: organizational belonging, which includes:

1. use of job rotation techniques for satisfying succession planning in organization, 2. Respect to employees and their position in organization, 3. Employees' tendency to tasks they have been submitted, 4.Consistency between salary and work, 5.Facilitation of innovation and creativity in employees, 6. Positive environment and friendly working relations among employees,

Sixth factor: working environment, which includes the following indices:

1. employees' satisfaction with their works, 2. Necessary skills for doing their tasks, 3. Attention to employees' 
health and safety, 4. Presence of an appropriate organizational atmosphere within the organization, 5.Compatibility between gender and work type, 6 . Easy access to organizational resources which are related o work,

Seventh factor: appreciation and recognition, which includes:

1. enrichment of elements related to responsibilities, 2. Compatibility of employees' occupational promotion and their competencies, 3.Consistency between appreciation of employees and their attempts, 4. Appropriate distribution of facilities within organization,

Eighth factor: participation and group work, which includes the followings: decisions

1. employees' cooperation in improvement of organizational affairs, 2. Use of employees' ideas and opinion in

2. compatibility of employees' responsibilities in organization

The most appropriate model for employees' empowerment in Mazandaran province airports:

We used confirmatory factor analysis (in LISREL software) in order to investigate latent variables of empowerment model which includes empowerment (as internal variable) and external variables including: clarity and significance of job, communications, job security, significance of job activities, organizational belonging, working environment, appreciation and recognition, participation and group work. As it can be seen in the standardized values model (figure 2), all variables have direct relationship with empowerment.

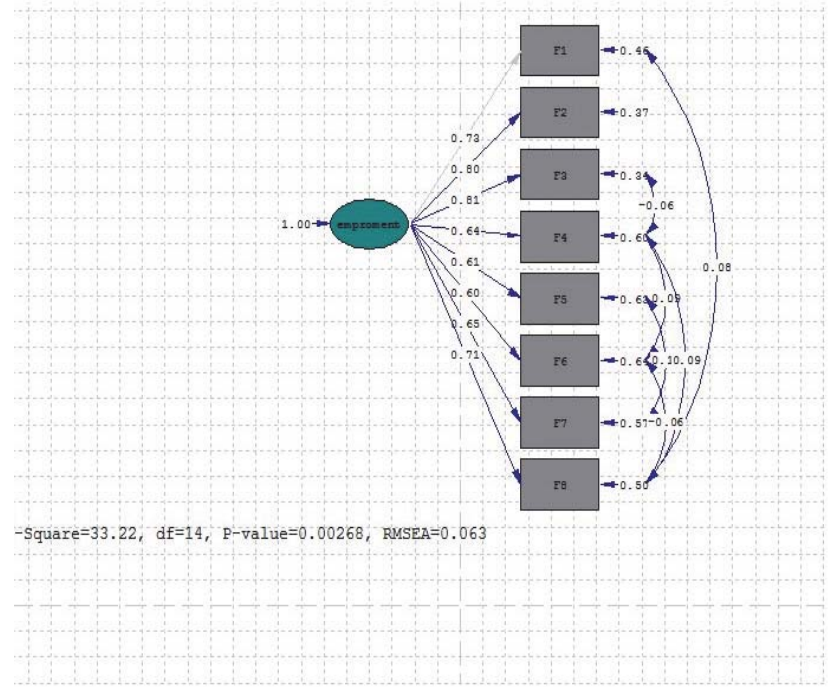

Figure 2. Standardized values model

Values of the final model have been collected in table 3.

Table 3. Values of the final model

\begin{tabular}{|c|c|c|c|c|c|}
\hline Predicted variance & $\mathrm{T}$ & Standard error & Standardized parameter & Parameter estimation & factor \\
\hline 0.56 & 11.18 & 0.28 & 0.75 & 2 & $\mathrm{~F} 1$ \\
\hline 0.64 & 10.49 & 0.19 & 0.80 & 1.85 & $\mathrm{~F} 2$ \\
\hline 0.66 & 10.58 & 0.27 & 0.81 & 2.18 & $\mathrm{~F} 3$ \\
\hline 0.41 & 12.10 & 0.27 & 0.64 & 1.50 & $\mathrm{~F} 4$ \\
\hline 0.37 & 12.17 & 0.23 & 0.61 & 1.35 & $\mathrm{~F} 5$ \\
\hline 0.36 & 12.35 & 0.29 & 0.60 & 1.38 & $\mathrm{~F} 6$ \\
\hline 0.42 & 11.91 & 0.15 & 0.65 & 1.22 & $\mathrm{~F} 7$ \\
\hline 0.50 & 11.38 & 0.09 & 0.71 & 1.11 & $\mathrm{~F} 8$ \\
\hline
\end{tabular}

According to data summarized in table above, all path coefficient values are statistically significant considering t value (in lower than 0.01 level). Furthermore, considering the standardized path coefficients (factor loadings), we can conclude the relative importance of the observed variables as indices of infrastructural factors. 


\section{Fit Indices for Confirmatory Factor Analysis Model}

We tried to improve the model by releasing some parameters based on adjustment indices in order to fit the model completely. LISREL software package introduces many indices for fitness of model. Table 4 refers to the most important indices.

Table 4. Indices for fitting employees' empowerment model in Mazandaran Province airports

\begin{tabular}{|c|c|c|c|}
\hline Feature & Estimation & Acceptable Range & Result \\
\hline Kai-square(x2) & 33.22 & IDF $<22 x$ & supported \\
\hline Root mean square error approximation(RMSEA $\left.{ }^{1}\right)$ & 0.063 & RMSEA $>0.09$ & supported \\
\hline Root Mean Square Residual $\left(\mathrm{RMR}^{2}\right)$ & 0.030 & $\mathrm{RMR}<0.05$ & supported \\
\hline Normal Fit Index $\left(\mathrm{NFI}^{3}\right)$ & 0.99 & $\mathrm{NFI}>0.90$ & supported \\
\hline Non- Normal Fit Index $\left(\mathrm{NNFI}^{4}\right)$ & 0.98 & NNFI $>0.90$ & supported \\
\hline Comparative Fit Index $\left(\mathrm{CF}^{5}\right)^{5}$ & 0.99 & CFI $>0.90$ & supported \\
\hline Goodness of Fit Index $\left(\mathrm{GFI}^{6}\right)$ & 0.98 & GFI $>0.90$ & supported \\
\hline Incremental Fit Index $\left(|\mathrm{F}|^{7}\right)$ & 0.99 & $\mathrm{IF} \mid>0.90$ & supported \\
\hline Adjusted Goodness of Fit Index)AGFI8( & 0.94 & AGFI>0.85 & supported \\
\hline
\end{tabular}

\section{References}

Bartlett, M.S.(1950). Tests of significance in factor analysis. British Journal Psychology, 3, 77-85.

Cartwrith, Roger (2002). Empowerment.Easton publishing And Satisfaction. Academy of Management Journal, 47(3), 332-349.

Conger Jay.\&Kanun go Rabinder, (1988), the Empowerment process: Integration theory \& Practice, Academy of Management Review, Vol. 13. No.3.

Drydyk, j. (2008). Empowerment and power: some conceptual analysis. Carleton university. OttawaEngineering, 39(2), 204-210.

Ergenli, A, Saglam, G \&Selin, M 2007, 'Psychological empowerment and its relationship to trust in immediate managers', Journal of Business Research, vol. 60, pp.Group, Inc.Its Inducement, and Consequences on Customer Relationships. A Thesis

Farhangi, Ali Akbar and eskandari, Mojtaba (2003). An introduction to empowerment in management and its models, quarterly of management studies, numbers 39 and 40.

Johnson, J. V. (1997). Empowerment in future work life, Scand J Work Environment Health 1997, vol23, suppl4

Kanooni, Arman (2005). The Employee Empowerment in Information Technology Department.Capella University.COMP8004 Managing and Organizing People.

Karakoc, Nihat (2009). Employee Empowerment and Differentiation in Companies: A Literature Review and Research Agenda. Enterprise Risk Management, 1(2), E1

Lawson, Karen (2006). 4 Keys to Employee Empowerment. Lawson Consulting

Management Review, 23( 3 ) 1999.

Mishra A.K ., Spreitzer G.M .;Explaining how survivors respond to downsizing:

Narayan, Deepa (2005). Measuring empowerment, cross- disciplinary perspectives. Washington, D. C: The Worth Bank.

Norouzi, Mojtaba, (2005). Employees' empowerment, educational and research quarterly of Controller, number 19.

Pak Tinat, Eghbal; FathiZadeh, Alireza (2008). Employees' empowerment: necessities and solutions, management quarterly, fifth year, number 11.

Seibert, Scott E., Silver, Seth R. \& Randolph, W. Alan (2004). Taking Empowerment To The Next Level: A Multiple-Level Model Of Empowerment, Performance,

Spreitzer, Gretchen \&Doneson, David (2005).Musings on the Past and Future of Employee Empowerment in Tom, Cummings (ed.), the Handbook of Organizational Development. Thousand Oaks: Sage.Submitted to the Faculty of Drexel University

Thamizhmanii, S. \& Hasan, S. (2010). A Review on an employee empowerment in The roles of trust, empowerment, justice, and work redesign ; The Academy of TQM practice. Journal of Achievements in Materials and Manufacturing

\footnotetext{
1-Root Mean Square Error of Approximation

2. Root Mean Square Residual

3-Normal Fit Index

4-Non- Normal Fit Index

5-Comparative Fit Index

6-Goodness of Fit Index

7-Incremental Fit Index

8-Adjusted Goodness of Fit Index
} 